\title{
Riscos ocupacionais dos técnicos em radiologia na assistência ao portador de múltiplos traumas
} Occupational risks of radiology technicians in care for patients with multiple trauma

Tiago Jorge Anderson* Alessandra Mendes de Barros* Fernanda Hannah da Silva Copelli* Juliana Almeida Coelho de Melo*

\begin{abstract}
Resumo
Este estudo objetivou identificar e dar visibilidade aos principais riscos ocupacionais de técnicos em radiologia, associados à assistência ao paciente portador de múltiplos traumas, em um serviço hospitalar de radiologia convencional. Pesquisa exploratório-descritiva com abordagem qualitativa. A coleta de dados ocorreu por meio da técnica de observação participante dos atendimentos efetuados pelos técnicos em radiologia num serviço de radiologia convencional de um hospital geral de Florianópolis entre maio e setembro de 2012. As observações que caracterizaram exposição a risco ocupacional foram descritas em diário de campo sendo posteriormente aproximadas e comparadas com o referencial teórico contido na Portaria N 25/1994. Constatou-se que os riscos ocupacionais a que se encontram expostos os técnicos em radiologia na assistência ao portador de múltiplos traumas estão relacionados à exposição à radiação ionizante, fluídos corporais e riscos ergonômicos, negligencia ao uso de equipamento de proteção individual e defeitos nos equipamentos. Os técnicos em radiologia tornam-se mais vulneráveis aos riscos ocupacionais quando prestam assistência ao paciente politraumatizado.
\end{abstract}

Palavras-chave: Riscos Ocupacionais. Tecnologia Radiológica. Saúde do Trabalhador.

\begin{abstract}
This study aimed to identify and give visibility to the main occupational hazards of radiology technicians, associated with the care of multiple trauma patient with a hospital department of conventional radiology. Exploratory and descriptive research with a qualitative approach. The data were collected through participant observation technique of calls made by radiology technicians in conventional radiology service of a general hospital in Florianópolis between May and September 2012. The observations that have characterized exposure to occupational risk were described in journal field subsequently estimated and compared with the theoretical framework contained in Decree No 25/1994. It was found that the occupational risks to which they are technicians exposed in radiology in the care of multiple traumas carrier are related to exposure to ionizing radiation, body fluids and ergonomic risks, neglects to personal protective equipment use and defects in equipment. The radiology technicians become more vulnerable to occupational risks when assisting polytrauma patients.
\end{abstract}

Keywords: Occupational Risks. Technology, Radiologic. Occupational Health.

DOI: 10.15343/0104-7809.20164001106113

* Universidade Federal de Santa Catarina. Florianópolis, Santa Catarina, Brasil.

Os autores declaram não haver conflitos de interesse. 


\section{INTRODUÇÃO}

O reconhecimento prévio dos riscos ocupacionais que geram desgastes à saúde dos trabalhadores, é um dos principais meios para prevenir adoecimentos e garantir a promoção da saúde no trabalho. Visto que, a grande chave para a saúde dos trabalhadores é antecipar a identificação dos riscos inerentes ao seu processo de trabalho para intervir precocemente na realidade, com o objetivo de desenvolver condições seguras aos trabalhadores'.

Os riscos ocupacionais, podem ser ou estar ocultos por ignorância, por falta de conhecimento, ou ainda, de informação, situação em que o profissional trabalhador sequer suspeita da sua existência. Pode, por sua vez, estar latente, o qual só se manifesta e causa danos em situações de emergência ou condições de estresse. E o risco pode ainda ser real, conhecido de todos, porém, sem possibilidade de controle, dado aos custos que representa para a instituição ou por falta de vontade política ${ }^{2}$.

Os riscos encontrados em um serviço de radiologia são bastante amplos, já que incorporam riscos relativamente comuns do ambiente laboral hospitalar e riscos específicos dessa atividade, como por exemplo, a exposição à radiação ionizante ${ }^{3}$.

Dentre os riscos ocupacionais comuns, temos àqueles associados ao ambiente de trabalho e aos aspectos ergonômicos, como levantamento de peso, sobretudo na ajuda aos doentes com mobilidade reduzida, horário de trabalho rotativo, trabalho com máquinas e equipamentos e pressão sobre a produtividade dos trabalhadores, particularmente em urgências e emergências nos dias de alta demanda ${ }^{4}$.

Desta forma, a saúde dos trabalhadores em radiologia é vulnerável por conta da exposição aos riscos presentes no seu processo de trabalho3. Sabe-se que os técnicos em radiologia trabalham sob condições inadequadas, do ponto de vista de segurança, tais como a falta de sinalização indicando a utilização de radiação ionizante, ausência de vidro plumbífero, equipamentos de proteção individual em quantidade insuficiente e negligência no seu uso por parte de alguns trabalhadores, desatenção as precauções padrões ante os riscos presentes no setor de radiodiagnóstico e pouco conhecimento a respeito da legislação sobre segurança do trabalho ${ }^{3}$.

No ambiente hospitalar, o técnico em radiologia, em condições de trabalho associadas a urgência do atendimento de pacientes portadores de múltiplos traumas e/ou em risco de vida pode acabar por ter exacerbada a exposição a determinados riscos ocupacionais.

É conhecido que todo paciente portadores de múltiplos traumas deve ser submetido a exame radiológico após admissão hospitalar, desde que apresente estabilidade hemodinâmica mínima que permita seu deslocamento ao setor de radiologia, ou quando instável, acompanhado por pessoal capacitado para assisti-lo(4). Para a realização das incidências radiográficas solicitadas, os profissionais da radiologia necessitam efetuar adaptações em seu processo de trabalho, devido à gravidade da situação do paciente e uso de acessórios médicos, como colar de cervical, talas, maca rígida ${ }^{5}$.

É notório que a gravidade do paciente e sua dificuldade de mobilização, relacionados à necessidade de adaptação da rotina de realização de exames radiográficos, associados aos riscos ocupacionais comuns ao ambiente hospitalar e específicos a atividade do técnico em radiologia expõe o profissional da radiologia a vários riscos ocupacionais que devem ser identificados, a fim de evitar o desgaste destes trabalhadores.

Compreender as peculiaridades do processo de trabalho de uma classe profissional e como os riscos se encontram distribuídos ao longo deste processo é fator preditivo para promoção e prevenção da saúde dos trabalhadores. Esta premissa, por sua vez, permeia o cotidiano dos profissionais que atuam na área de saúde do trabalhador.

Neste aspecto, sabe-se que a enfermagem é capaz de reconhecer e buscar estratégias de transformação individual e social no campo de saúde do trabalhador6. Partindose, ainda, dos subsídios científicos e clínicos que a enfermagem possui, passíveis de serem aplicados nas distintas áreas que compreendem a saúde do trabalhador, destacam-se ambientes pouco explorados, como a radiologia hospitalar,
107 
foco do presente estudo, os quais não integram a ação cotidiana dos profissionais da área em questão.

Perante esta problemática e lacunas no conhecimento sobre o tema desejamos mediante esse estudo aumentar a visibilidade dos riscos ocupacionais que acometem os profissionais técnicos em radiologia, contribuindo para adoção de medidas de promoção, prevenção e proteção de saúde dos mesmos.

Nesse contexto, a questão norteadora da pesquisa foi expressa da seguinte forma: Quais são os riscos ocupacionais a que estão expostos os técnicos em radiologia durante o atendimento a pacientes portadores de múltiplos traumas?

Com vistas a responder à questão de pesquisa, foi elaborado como objetivo, identificar e dar visibilidade aos principais riscos ocupacionais dos técnicos em radiologia associados à assistência ao paciente portador de múltiplos traumas num serviço hospitalar de radiologia convencional.

\section{MÉTODO}

Tratou-se de um estudo exploratóriodescritivo com abordagem qualitativa. Realizou-se a pesquisa no serviço de radiologia convencional de um hospital geral de Florianópolis, referência em trauma e ortopedia, subordinado à Secretaria Estadual de Saúde de Santa Catarina no período compreendido entre maio e setembro de 2012. O hospital realiza cerca de 3400 exames de radiologia convencional mensalmente. Destes, 2500 exames são realizados em pacientes oriundos da unidade de pronto-socorro. No paciente portador de múltiplos traumas, é comum realizar duas incidências das seguintes estruturas corporais: coluna cervical, coluna torácica, coluna lombar, membros inferiores e superiores, além de uma única incidência de bacia e tórax.

Este serviço de radiologia convencional conta com três aparelhos de radiologia convencional, uma sala de digitalização e um total de 15 técnicos em radiologia. Foram incluídos no estudo 10 técnicos em radiologia que aceitaram participar da pesquisa de forma voluntária e que assinaram o termo de consentimento livre e esclarecido. Torna-se importante salientar que a instituição fornecia dosímetro individual para todos os trabalhadores expostos à radiação ionizante.

Como técnica de pesquisa, utilizou-se a observação dos atendimentos efetuados pela equipe de técnicos em radiologia, que caracterizaram assistência ao paciente portador de múltiplos traumas perfazendo um total de 100 horas de observação participante. Esta observação foi executada em diferentes turnos, de modo a incluir os diferentes profissionais participantes. Para nortear a observação utilizou-se um formulário próprio, contendo os diferentes riscos ocupacionais elencados na Norma Regulamentadora 9 (NR 9) (riscos físicos, químicos, ergonômicos, mecânicos e biológicos) e suas descrições.

Todas as situações de atendimento que caracterizaram exposição a risco ocupacional dos técnicos em radiologia na assistência ao paciente politraumatizado foram descritas em um diário de campo imediatamente após a observação.

O diário de campo é um instrumento que permeia a técnica de observação. Trata-se de um caderno de notas, em que o investigador, dia após dia, anota o que observa. Nele devem ser escritas impressões pessoais que se modificam ou não com o tempo, resultados de conversas informais, observações de comportamentos contraditórios, dentre outras ${ }^{7}$.

A vinculação dos dados se fez por semelhança, para posterior análise e interpretação das informações contidas em aproximação com o referencial teórico de riscos ocupacionais contidos na Portaria N 25/1994 do Ministério de Trabalho e Emprego (MET), que classifica os riscos em cinco grupos: riscos físicos, riscos químicos, riscos biológicos, riscos ergonômicos e riscos de acidentes8. Decidiu-se trabalhar com o conceito de risco ocupacional como referencial teórico devido ao fato de este ser o utilizado no modelo legal brasileiro vigente no contexto da Saúde do Trabalhador e da Medicina do Trabalho no Brasil. Após essa etapa, realizou-se a interpretação dos dados em 
inter-relação com a literatura pertinente.

Toda a pesquisa desenvolveu-se de acordo com a Resolução 196/96 do Conselho Nacional de Saúde e todos os participantes tiverem conhecimento sobre os propósitos da pesquisa. O projeto de pesquisa foi aprovado pelo Comitê de Ética do Instituto de Cardiologia, subordinado à Secretaria Estadual de Saúde de Santa Catarina, sob o número 104-2010 nos seus aspectos éticos e metodológicos.

\section{RESULTADOS E DISCUSSÃO}

Observou-se que um técnico em radiologia, com o intuito de agilizar a assistência ao paciente politraumatizado e concluir a execução das incidências solicitadas, se expôs a radiação ao feixe primário de radiação ionizante ao segurar o chassi radiográfico para a execução das incidências de membro inferior e superior. A permanência do técnico para garantir o correto posicionamento durante os exames foi observada também em estudo no qual a clientela atendida era composta por neuropatas ${ }^{9}$. Sabese que os profissionais, na sala de exame, devem posicionar-se de tal forma que nenhuma parte do corpo, incluindo extremidades, seja atingida pelo feixe primário sem que esteja protegida por $0,5 \mathrm{~mm}$ equivalentes de chumbo e também se proteger da radiação espalhada por vestimenta ou barreiras protetoras com atenuação não inferior a $0,25 \mathrm{~mm}$ equivalentes de chumbo ${ }^{1510-12}$.

Associado a condição de exposição ao feixe primário de radiação observou-se a negligência quanto ao uso de avental plumbífero por parte desse profissional. Considerando a quantidade de trabalho exigida durante a rotina de uma emergência, o não uso de equipamentos de proteção individual (EPI), pode tornarse habitual, mesmo quando disponíveis em número suficiente. Aqui vemos somar-se ao risco do ambiente de trabalho, a pressão exigida para a continuidade do serviço, sem interrupções, quando talvez pudesse ser em ritmo mais lento, para dar tempo ao trabalhador de se paramentar. Nesse ínterim, o sistema de proteção radiológica deve se empenhar em manter a exposição ocupacional abaixo do limiar recomendado, evitando-se os efeitos estocásticos e determinísticos produzidos pela radiação. Torna-se importante enfatizar que o uso de EPI ante o risco físico á radiação ionizante é condição imperiosa para reduzir a exposição a este risco ${ }^{13}$. Destaca-se ainda o treinamento anual e a educação continuada sobre proteção radiológica de todos os profissionais envolvidos, visando ao cumprimento do que a legislação preconiza como forma de proteger-se ao risco físico da radiação ionizante, que engloba o uso de EPI no processo de trabalho dos profissionais das técnicas radiológicas ${ }^{13-14}$.

A necessidade de prestar atendimento de urgência ao paciente portador de múltiplos traumas associada ao ritmo de trabalho intenso imposto pela alta demanda de pacientes levou a constatação da utilização do aparelho de raios $x$ convencional mesmo na presença de avarias para a execução de exames diagnósticos. Cita-se como exemplo, a realização de exame radiológico com a luz de colimação não funcionante. Sem este recurso, há a necessidade de abertura total do feixe de radiação $x$, que implica em mais estruturas expostas a esta forma de energia. Há, consequentemente, maior produção de radiação secundária, que gera aumento do risco de exposição à radiação ionizante ${ }^{13}$. Constatou-se esta prática no estudo de Pacheco, Santos e Tavares Neto, em que o técnico não estabelecia delimitação precisa do local de incidência do feixe de raio $x$, uma vez que a lâmpada de colimação estava queimada ${ }^{15}$. Estudo de Santos Junior indicou a falta de sistematização de rotinas preventivas para manutenção de equipamentos emissores de radiação x, conforme preconizado pela Portaria da Secretaria de Vigilância Sanitária/ Ministério da Saúde nº453 (SVS/MS nº453), de 1 de junho de 1998, como fator de risco ocupacional em centros de radiodiagnósticos ${ }^{10,16}$.

A prática de usar equipamentos emissores de radiação x com defeitos não é recomendável, pois expõe paciente e profissional aos riscos inerentes à radiação ionizante devido ao aumento de produção de radiação espalhada. Sabe-se que a exposição à radiação ionizante sempre causa danos às células. Por essa razão, deve-se procurar reduzir ao máximo a exposição profissional a radiação ionizante, mesmo quando os níveis de exposição aos
109 
raios $\mathrm{x}$ forem baixos, é importante enfatizar que a exposição crônica pode levar a doenças malignas e também à catarata tempo ${ }^{13}$.

Ainda sobre o risco de exposição, temos o que preconiza a Portaria 518/2003 do Ministério do Trabalho e Emprego (MTE), publicada no Diário Oficial da União (DOU) de 07/04/2003, que adota como atividades perigosas, entre outras, as atividades de operação com aparelhos de raios $\mathrm{x}$ que constam no quadro de atividades e áreas de riscos apresentado na NR 16. Essa Portaria destaca que qualquer exposição do trabalhador às radiações ionizantes é potencialmente prejudicial à sua saúde, considerando que mesmo as novas tecnologias introduzidas nos aparelhos de radiologia e nos EPI não permitem a eliminação desse risco ${ }^{17-18}$.

Durante a apreciação do processo de trabalho dos técnicos em radiologia, observouse, no que se refere aos riscos biológicos, exposição a fluídos corporais, principalmente sangue, relacionados à presença de fraturas expostas, lacerações e outros tipos de lesões no paciente portador de múltiplos trauma. O risco de exposição a fluídos biológicos está presente em diferentes ambientes de trabalho em saúde, pois o ambiente hospitalar concentra pacientes com doenças infecciosas e infectocontagiosas ${ }^{14}$. Os profissionais de saúde são potencialmente vulneráveis aos agentes biológicos, mais frequentemente profissionais que entram em contato direto com os pacientes, tais como os técnicos em radiologia ${ }^{19}$.

No processo de trabalho dos técnicos em radiologia, evidenciou-se ausência de luvas de procedimento para manuseio do paciente portador de múltiplos traumas em alguns momentos. Em outras conjunturas, as luvas estavam presentes, porém não eram usadas durante a realização de exames no qual havia exposição a fluídos corporais. Observou-se também que os chassis radiográficos e a mesa de raios $x$, quando expostos ao sangue, não passavam por um processo de desinfecção adequado após o uso, devido à ausência de desinfetantes ou a própria não realização da desinfecção recorrente. Todas estas situações, ainda eram agravadas quando associadas à necessidade da urgência no atendimento ao paciente politraumatizado e ritmo intenso de trabalho devido ao alto número de pacientes.
Dentre as causas que levam à exposição ao material biológico temos: manejo rápido no atendimento, desconhecimento da clínica e gravidade do paciente, autoconfiança demasiada, falta de uso de EPI, descuido, inadequação de materiais, correria do plantão, falta de esclarecimento sobre biossegurança, precarização da equipe, dúvidas relacionadas ao mecanismo de transmissão de algumas doenças, ausência de educação continuada, carga excessiva de trabalho e não adoção de medidas preventivas $^{3,19}$. Sabe-se ainda que o trabalhador de saúde tem mostrado resistência à utilização das normas de biossegurança e subestimam o risco de infectar-se ${ }^{19}$. Os profissionais de saúde assumem comportamentos de risco devido à familiaridade com o ambiente insalubre ou de risco, o que diminui a percepção destes profissionais acerca da necessidade de adotar medidas preventivas para sua própria segurança ${ }^{19}$.

Elencou-se, também, na observação das práticas assistenciais do técnico em radiologia, ausência de local adequado para higienização das mãos. Os técnicos em radiologia, nas situações de contato com secreções na assistência ao paciente politraumatizado para higienizar as mãos, deviam deslocar-se até o banheiro dos funcionários para efetuarem a lavagem destas. Este grande percurso, somado à alta demanda de pacientes, contribuiu para que a higienização das mãos não fosse rotineira. A Norma Regulamentadora 32 explicita que todo local onde exista a possibilidade de exposição a agentes biológicos deve ter lavatório exclusivo para higienização das mãos, providos de água corrente, sabonete líquido, toalha descartável e lixeira provida de sistemas de abertura sem contato manual ${ }^{16}$.

No processo de trabalho dos técnicos em radiologia, na assistência ao paciente traumatizado, é comum a necessidade de transferir o paciente da maca para a mesa de exames, sendo que este constitui um fator de risco ergonômico. Para executar a transferência do paciente, é recomendável que a mesa e a maca estejam na mesma altura. Observouse, na prática, que as macas não possuíam mecanismos que possibilitassem regulagem de altura, tão pouco, a mesa do equipamento de radiologia convencional. Isso impedia que 
fossem respeitados os princípios da mecânica corporal, o que acaba por gerar sobrecarga nas articulações e na coluna vertebral. Um sistema de regulagem de altura e movimentação para as macas e mesas de exame de acordo com o tipo de procedimento a ser realizado e com a altura do trabalhador facilita a transferência de pacientes e diminuem as forças aplicadas sobre a coluna vertebral ${ }^{16}$.

Além da ausência de mecanismos de regulagem de altura, muitas macas apresentavam avarias, como travas e rodas funcionando inadequadamente. Para efetuar travamento das macas, os profissionais utilizavam seu próprio corpo. Para movimentá-las, devido ao não funcionamento das rodas, os técnicos em radiologia, assim como os demais profissionais, necessitam erguer as macas, o que exigia deles o emprego de um esforço maior. Sobre este aspecto orienta-se para evitar a ocorrência de distúrbios osteomusculares que se evite a utilização de mobiliários e equipamentos improvisados, além de que se atente para uma manutenção adequada e periódica dos equipamentos hospitalares ${ }^{15}$.

Observou-se também número reduzido de trabalhadores, para efetuar a transferência do paciente para a realização de exames. Em muitas situações, a transferência de pacientes era realizada apenas por dois trabalhadores. Em alguns momentos, mesmo não havendo trabalhadores suficientes para efetuar a transferência do paciente, aqueles que traziam o paciente ao serviço de radiologia não se prestavam a auxiliar nesta tarefa. Neste quesito, é mister afirmar que a escassez da força de trabalho no setor saúde acaba por promover este tipo de situação?

No que tange à mecânica corporal, evidenciou-se que para efetuar a transferência do paciente na sala de exame de raio $x, a$ equipe necessitava manipular o paciente acima da altura dos ombros em virtude de macas excessivamente altas. Neste aspecto estudo demonstrou que na transferência de pacientes se combinam forças de tração, com flexão e tronco e extensão excessiva de braços devido ao não respeito de princípios da mecânica corporal. Estes fatores aumentam o torque nas articulações interverterbrais da coluna lombar e o estiramento da musculatura que podem levar ao desenvolvimento de doenças osteomusculares ${ }^{3}$.

Destacou-se também a exigência de produção em ritmo de trabalho acelerado, nas situações no qual havia mais de um politrauma esperando para realização de exames. Esse ritmo de trabalho era intensificado quando um dos equipamentos de raios $x$ convencional encontrava-se fora de uso ou em manutenção. Era evidente que a necessidade de garantir a assistência, mesmo com condições inadequadas de trabalho, gerava desgastes fisiológicos e psíquicos aos técnicos em radiologia, além de aumentar o risco de exposição aos demais riscos presentes no contexto do trabalho observado. A literatura demonstra que a sobrecarga imposta aos técnicos em radiologia, pressão sobre a produtividade, particularmente em urgências nos dias de maior fluxo, o lidar com situações no qual se tem de realizar exames em pacientes politraumatizados e/ou em risco de vida levam a desgaste psicológico ${ }^{20}$. Afinal, nas situações de urgência, o estresse relacionado a ansiedade dos pacientes em serem atendidos, pode gerar conflitos entre profissionais da saúde e pacientes ${ }^{16,20}$.

Diante da diversidade dos riscos apresentados na assistência ao paciente pelo técnico em radiologia, recomenda-se que o que é preconizado pela legislação de saúde do trabalhador seja adotado pelas instituições. Orienta-se também que programas de educação continuada e permanente sejam realizados mediante o reconhecimento prévio dos riscos a que se encontram expostos os profissionais das técnicas radiológicas. Destaca-se também especial atenção ao processo de formação educacional destes profissionais, que deve incluir ações crítico-reflexivos para o cuidado de si no que tange à saúde do trabalhador.

\section{CONCLUSÃO}

Ao concluir esse estudo, percebe-se que levando em consideração as características do processo de trabalho em saúde, sobretudo do profissional técnico em radiologia e considerando as peculiaridades do processo de trabalho em uma unidade de referência ao paciente portador de múltiplos traumas,

111 
encontraram-se problemas no que tange a vulnerabilidade a riscos ocupacionais.

A exposição à radiação ionizante na unidade pesquisada dava-se, principalmente, durante a realização de exames em que o profissional segurava o chassi radiográfico. Além do desconhecimento dos princípios

\section{REFERÊNCIAS} 2013; 21(6): 1290-1297. Enferm.2008;16(5):923-28. 2011; (20)1:68-75. dos equipamentos devido à ausência de desinfetantes ou a própria não realização da desinfecção recorrente.

Dentre as situações em que foi observada exposição a riscos ocupacionais, a maioria apresenta soluções passíveis de serem implantadas nos serviços de radiologia, tendo em vista a disponibilidade no Brasil de recursos materiais e humanos, além de legislação específica que aborda o tema de saúde e segurança do trabalhador. Neste contexto destaca-se a equipe responsável pela saúde do trabalhador nas instituições de saúde, no qual se inclui o Enfermeiro do Trabalho. Compete a esses profissionais reconhecer previamente os riscos a que os profissionais se encontram expostos e promover e manter a saúde dos trabalhadores, principalmente o daquelas categorias no qual os riscos ainda não foram totalmente minimizados.

O tema Segurança dos Trabalhadores da área de Radiologia ainda é pouco explorado entre os profissionais da saúde. Sendo um assunto de extrema importância para os profissionais da área e a população, acreditase que os resultados aqui apresentados são considerados relevantes, pois exploram dados que podem auxiliar os serviços a refletir sobre o assunto e investir na construção de ambientes saudáveis ao trabalhador.

1. Mininel VA, et al. Cargas de trabalho, processos de desgastes e absenteísmo-doença em enfermagem. Revista Latino-Am Enferm.

2. Nichiata LYI, Bertolozzi MR, Takahashi RF, Fracolli LA. A utilização do conceito vulnerabilidade pela enfermagem. Rev Latino-Am

3. Brand Cl; Fontana RT; Santos AV. A saúde do trabalhador em radiologia: algumas considerações. Tex cont enferm. Florianópolis.

4. Areosa J. Riscos ocupacionais em radiologia: estudo de caso num hospital português. Tempo social Rev Sociol USP. 2011; (23) 2: 297-318.

5. Santoro DC; Fernandes AG; Rufino D. Atendimento pré e intra-hospitalar de adultos vítimas de trauma. Pro enf saúde do adulto. $2011 ; 6(2), 97-146$.

6. Rocha LP, et al. Utilização de equipamentos de proteção individual por frentistas de postos de combustíveis: contribuição da enfermagem. Tex cont enferm. Florianópolis. 2014; 23(1), 193-202.

7. Minayo MCS. Pesquisa qualitativa em saúde, 2013; Hucitec: São Paulo, 13 ed.

8. Ministério do trabalho e emprego; Secretaria de Inspeção Do Trabalho. Portaria 25. Brasília (Brasil) de 29 de dezembro de 1994.

9. Fernandes GS; Carvalho ACP; Azevedo ACP. Avaliação dos riscos ocupacionais de trabalhadores de serviços de radiologia. Radiologia brasileira, 2005; 38(4): 279-281.

10. Brasil, Ministério da Saúde. Portaria 453, 1 jun. 1998.

11. Diretrizes de proteção radiológica em radiodiagnóstico médico e odontológico. Brasília: Diário Oficial da República Federativa do Brasil, Poder Executivo, 02 jun. 1998, seção 1, p. 29.

12. Brasil, Ministério do Trabalho e Emprego. Portaria 485, 11 nov. 2005. NR 32: Segurança e saúde no trabalho em serviços de saúde. Diário Oficial da República Federativa do Brasil, Poder Executivo, Brasilia, DF, 16 nov. 2005, seção 1, p. 80.

13. Souza E; Soares JPM. Correlações técnicas e ocupacionais da radiologia intervencionista. Jornal Vascular Brasileiro, 2008; 7 (4): 
341-350.

14. Flor RC; Gelbcke FL. Tecnologias emissoras de radiação e a necessidade de educação permanente para uma práxis segura de enfermagem radiológica. Rev Bras Enferm, 2009; 62(5): 766-70.

15. Oliveira SR; Azevedo ACP; Carvalho ACP. Elaboração de um programa de monitoração ocupacional em radiologia para o Hospital universitário Clementino Fraga Filho. Rad. Bras. 2003; 36(1): 27-34.

16. Santos Junior BJ, et al. Riscos ocupacionais em centros de radiodiagnóstico. Rev Enferm. UERJ, 2010; 18 (3): 365-370.

17. Brasil, Ministério do Trabalho e Emprego. Portaria 518, 7 abr.2003. Atividades e operações perigosas com radiações ionizantes ou substâncias radioativas: atividades/áreas de risco.

18. Diário Oficial da República Federativa do Brasil, Poder Executivo, Brasilia, DF, 07 abr. 2003, seção 1, p. 104.

19. Miranda FMD; Stein Junior AV; Petreli S; Pires MR; Pires LGS; RibeiralBN; Sarquis LMM; Felli VEA; Oliveira MCX. Uma contribuição à saúde dos trabalhadores: um guia sobre a exposição aos fluídos biológicos. Rev Esc Enferm. USP. 2011; 45(4):1018-22.

20. Areosa J. Riscos ocupacionais em radiologia: estudo de caso num hospital português. Tempo social Rev Sociol USP. 2011; (23) 2:

297-318.

Recebido em 13 de abril de 2015. Aprovado em 18 de março de 2016. 